\title{
New digital platform for dentists to get the ear of ministers
}

Dentists and anyone working for the NHS will be able to have their say on how the health service can be improved, through a new digital platform.

The government launched the new TalkHealthandCare ${ }^{1}$ platform on 10 September 2018 which staff can use to post any ideas, questions or challenges they have for ministers in an attempt for them to influence future policy.

The platform, available on computers, phones and tablets, will continually update to reflect the views and ideas of staff while also including information about events, forums and webinars for staff across the country.

The Department said the platform had been launched following feedback from staff that showed they often felt unvalued at work and a new workforce panel of staff has also been established who will meet with Health and Social Care Secretary Matt Hancock to act as a sounding board on issues affecting health and care staff.

Some of the known issues that

TalkHealthandCare will be seeking views on include:

- Improving shift patterns and juggling home and work lives

- Speeding up the use of helpful technologies that cut out paperwork

- Training and development

- Determining how to make staff feel safe and secure at work.

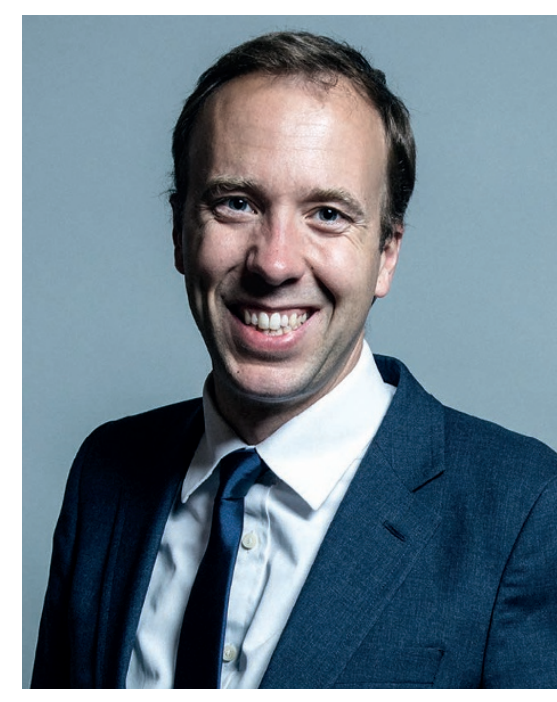

Health and Social Care Secretary Matt Hancock

Hancock said: 'Too often health and care employers, despite the NHS being the world's fifth largest employer, don't get this right. It's time we hear from health and care staff about what they really have to say about the jobs that are at the heart of this country.

'Nobody knows what needs improving more than hard-working staff themselves, so my message is clear: we are listening to you, we want your views, and we will use them to ensure the long-term plan for the NHS helps you.'

1. Department of Health and Social Care. Talk Health and Care. Available at https://dhscworkforce. crowdicity.com/hubbub/summary (accessed September 2018).

\section{Healthcare leaders gathering invites dentists}

A gathering of leaders in healthcare are keen to ensure that dentists are part of the multiprofessional team attending this year's 'Leadership in Healthcare' event.

The conference is being held at the ICC in Birmingham from 14 to 16 November 2018.

The event will include a masterclass day, delivering high-quality learning delivered by experienced practitioners; high-profile keynote speakers; the chance to network with healthcare leadership and management peers; and CPD points.

The emphasis at the event is very much on the development and importance of leadership within the various healthcare disciplines including dentistry.

More information about the conference is available at https://www.leadersinhealthcare. com/register-now (accessed on 11 September 2018). 